\title{
The Effects of Income Inequality on Education Policy and Economic Growth
}

\author{
Katsuyuki Naito, Keigo Nishida \\ Graduate School of Economics, Kyoto University, Kyoto, Japan \\ Email: k.naito.71@gmail.com, k.nishida@ft7.ecs.kyoto-u.ac.jp
}

Received November 30, 2011; revised December 20, 2011; accepted December 28, 2011

\begin{abstract}
This paper presents a simple model to investigate the relationship among initial income inequality, education and economic growth. Public expenditure on education is determined through majority voting. Although preferences of individuals are not single-peaked, the individual with the median income becomes the decisive voter. Our model predicts that high initial inequality has a negative impact on education expenditure and therefore retards economic growth.
\end{abstract}

Keywords: Income Inequality; Majority Voting; Human Capital Accumulation; Economic Growth

\section{Introduction}

The relationship between initial levels of income inequality and economic growth is a central question in growth and development literature. Many political economists have addressed this question by analyzing how income inequality affects the size of redistribution. Standard politico-economic theories predict that, under majority voting, high income inequality is associated with a large scale of redistribution policies as the poor majority favors it. Persson and Tabellini [1] argue that income redistribution creates adverse incentive for investments and therefore high income inequality is harmful for growth. However, redistribution policies may promote economic growth if they are practiced through the provision of public goods that can enhance future productivity. SaintPaul and Verdier [2] construct a model in which public education is the channel of redistribution. In their model, high income inequality implies strong support for public education, which facilitates human capital accumulation and economic growth. In contrast to these theories, the hypothesis that high inequality is associated with redistribution is not supported by data. For example, crosscountry regressions by Easterly [3,4] show that higher inequality leads to lower levels of public goods, education, per capita income and growth rates. This suggests the necessity for further investigations on how income inequality affects public policies and growth.

This paper proposes a simple model to reconcile the theory and evidence, and analyzes the relationship among income inequality, human capital accumulation

\footnotetext{
${ }^{1}$ Many empirical studies such as Hanushek [5] find a positive effect of parental human capital on the return from education.
}

and economic growth in a politico-economic framework. In the model, the heterogeneity of human capital across individuals is the only source of income inequality. We focus on two features of education. The first one is a fixed cost of education. We consider a situation in which individuals must pay tuition fees to have access to education services although they are provided by the government. This aspect of education is particularly relevant to post-compulsory education, such as high school and university education. The second feature is that the return from education is positively correlated with the level of human capital inherited from parents. ${ }^{1}$ These two features play a key role in the determination of the size of education services under majority voting.

The main result of this paper is that high initial levels of inequality cause less publicly provided education services, or lower tax rates. In our model, the individual with median income is the decisive voter although preferences for tax rates are not single-peaked. When inequality is high and the income of the median voter is low, he or she does not prefer a high tax rate to enhance education. This is because the median voter cannot cover the fixed cost of education or the private return from education is too low due to his or her low level of inherited human capital. High inequality is therefore harmful for human capital accumulation and growth, which is in contrast to the result of Saint-Paul and Verdier [2].

\section{The Model}

We consider an overlapping generations economy in which individuals live for two periods. They are heterogeneous only with respect to their human capital within 
each generation. Each individual has one parent and one child, and the size of each generation is normalized to one. In the first period, individuals make no economic and political decisions, but receive education if their parents decide to invest in human capital of their children. In the second period, individuals inelastically supply their human capital to a final good sector and decide whether to invest in education for their children. Using human capital, $h$, the final good sector produces according to a linear production function, $y=h$, where $y$ is the output. The final good market is perfectly competitive, and therefore, the wage for one unit of human capital is one. Individuals derive utility from consumption in their second period and human capital of their children. The preference of individual $i$ born in period $t$ are represented by a linear utility function,

$$
U\left(c_{i t+1}, h_{i t+1}\right)=c_{i t+1}+h_{i t+1},
$$

where $c_{i t+1}$ and $h_{i t+1}$ are consumption in the period $t+1$ and human capital of his/her child, respectively.

The investment in education requires one unit of the final good as a fixed cost. Individuals must self-finance the cost because human capital of their children is not valid collateral to lenders. The consumption of individual $i$ born in period $t$ is given by

$$
c_{i t+1}=\left\{\begin{array}{lr}
\left(1-\tau_{t+1}\right) h_{i t}-1 \text { if investing in education, } \\
\left(1-\tau_{t+1}\right) h_{i t} & \text { otherwise, }
\end{array}\right.
$$

where $\tau_{t+1}$ is the proportional labor income tax rate at period $t+1$. Remember that $h_{i t}$ is the human capital of individual $i$ born in period $t$, which is supplied to the final good sector at period $t+1$.

The government manages an education sector. By levying a labor income tax on parental individuals, the government finances public expenditure which raises the productivity of the education sector. Let the distribution of $h_{i t}$ be denoted by $F_{t}$. The average human capital, $h_{t}$, is then given by $h_{t} \equiv \int h_{i t} \mathrm{~d} F_{t}\left(h_{i t}\right)$, and the tax revenue is $\tau_{t+1} h_{t}$. Assuming that the government budget is balanced in each period, we obtain

$$
G_{t+1}=\tau_{t+1} h_{t},
$$

where $G_{t+1}$ is the public expenditure on the education sector.

Individual $i$ whose parent pays the fixed cost of education can have access to education services and accumulate human capital according to the following human capital production function:

$$
h_{i t+1}=\left(\frac{G_{t+1}}{h_{t}}\right)^{\theta} h_{i t}+h_{i t}, \theta \in(0,1) .
$$

Notice that the human capital production function depends on the ratio of public education expenditure to average human capital. The interpretation is as follows. The government must hire teachers in the public education system. On the condition that the wage per teacher is equal to the average wage in the economy, the ratio $G_{t+1} / h_{t}$ represents the number of teachers in the public education system. From (3) and (4), human capital of individual $i$ born in period $t+1$ who receives education is given by

$$
h_{i t+1}=\tau_{t+1}^{\theta} h_{t}+h_{t} .
$$

In contrast, individuals just inherit their parental human capital if their parents do not invest in education:

$$
h_{i t+1}=h_{i t} \text {. }
$$

Individuals with $h_{i t}<1 /\left(1-\tau_{t+1}\right) \equiv H_{1}\left(\tau_{t+1}\right)$ cannot afford to invest in education. The threshold $H_{1}$ is increasing in $\tau_{t+1}$. A high level of $\tau_{t+1}$ reduces disposable income of individuals and makes more individuals unable to invest in education. In contrast, individuals with $h_{i t} \geq H_{1}\left(\tau_{t+1}\right)$ are able to invest in education.

From (1), (2) and (5), the welfare of an individual with $h_{i t}$ who chooses to have their children receive education is given by

$$
V^{E}\left(\tau_{t+1}, h_{i t}\right)=\left(1-\tau_{t+1}\right) h_{i t}-1+\tau_{t+1}^{\theta} h_{i t}+h_{i t} .
$$

On the other hand, the welfare of an individual with $h_{i t}$ who chooses not to invest in education is given by

$$
V^{N}\left(\tau_{t+1}, h_{i t}\right)=\left(1-\tau_{t+1}\right) h_{i t}+h_{i t} .
$$

The welfare function $V^{N}$ is decreasing in $\tau_{t+1}$ since higher tax rates reduce the consumption in the second period. It is easy to see that individuals with $h_{i t} \geq$ $1 / \tau_{t+1}^{\theta} \equiv H_{2}\left(\tau_{t+1}\right)$ are willing to invest in education, while individuals with $h_{i t}<H_{2}\left(\tau_{t+1}\right)$ are not. Notice that the threshold $\mathrm{H}_{2}$ is decreasing in $\tau_{t+1}$. An increase in $\tau_{t+1}$ raises the return on education, and thus, makes more individuals willing to invest in education.

\section{Preferred Tax Rates}

We proceed to analyze the characteristics of a politicoeconomic equilibrium in which the level of labor income tax rate is determined under majority voting. Since schoolage individuals do not participate in voting in many countries, we assume that only individuals in the second period have voting rights. To characterize the politicoeconomic equilibrium, we need to identify the tax rate that each individual prefers the most. Let us define $\hat{\tau}$ and $\hat{H}$ by $H_{1}(\hat{\tau})=H_{2}(\hat{\tau})$ and $\hat{H} \equiv H_{1}(\hat{\tau})$.

First of all, for any $h_{i t}<\hat{H}$ and $\tau_{t+1} \in[0,1]$, $h_{i t}<\max \left\{H_{1}\left(\tau_{t+1}\right), H_{2}\left(\tau_{t+1}\right)\right\} \quad$ (see Figure 1). Any individuals with $h_{i t}<\hat{H}$ are unwilling or unable to have their children receive education and therefore prefer $\tau_{t+1}=0$.

We then investigate preferences of individuals with $h_{i t} \geq \hat{H}$. It is useful to define $\tau_{1}\left(h_{i t}\right)$ and $\tau_{2}\left(h_{i t}\right)$ by 


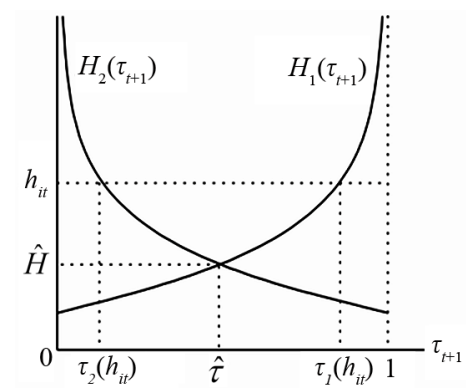

Figure 1. The features of $\mathrm{H}_{1}$ and $\mathrm{H}_{2}$.

$$
\begin{aligned}
& \tau_{1}\left(h_{i t}\right) \equiv\left(H_{1}\right)^{-1}\left(h_{i t}\right)=1-\frac{1}{h_{i t}}, \\
& \tau_{2}\left(h_{i t}\right) \equiv\left(H_{2}\right)^{-1}\left(h_{i t}\right)=h_{i t}^{-\frac{1}{\theta}} .
\end{aligned}
$$

For $0 \leq \tau_{t+1}<\tau_{2}\left(h_{i t}\right)$, an individual with $h_{i t}$ is unwilling to invest in education because the return from education is too low. For $\tau_{2}\left(h_{i t}\right) \leq \tau_{t+1} \leq \tau_{1}\left(h_{i t}\right)$, the individual is willing and able to invest in education. For $\tau_{1}\left(h_{i t}\right)<\tau_{t+1} \leq 1$, the individual cannot afford to invest in education because of the high labor income tax rate. The welfare of individual $i$ with $h_{i t} \geq \hat{H}$ is summarized as

$$
W\left(\tau_{t+1}, h_{i t}\right)=\left\{\begin{array}{cc}
V^{N}\left(\tau_{t+1}, h_{i t}\right) \text { if } & 0 \leq \tau_{t+1}<\tau_{2}\left(h_{i t}\right), \\
V^{E}\left(\tau_{t+1}, h_{i t}\right) \text { if } & \tau_{2}\left(h_{i t}\right) \leq \tau_{t+1} \leq \tau_{1}\left(h_{i t}\right), \\
V^{N}\left(\tau_{t+1}, h_{i t}\right) \text { if } & \tau_{1}\left(h_{i t}\right)<\tau_{t+1} \leq 1 .
\end{array}\right.
$$

We define $\tau^{*}$ by

$$
\frac{\partial V^{E}}{\partial \tau_{t+1}}\left(\tau^{*}, h_{i t}\right)=0 \Leftrightarrow \tau^{*}=\theta^{\frac{1}{1-\theta}} \in(0,1)
$$

in order to fully describe the preferred tax rate of individual $i$ with $h_{i t}$. It is clearly evident that $\tau_{1}\left(h_{i t}\right)$, $\tau_{2}\left(h_{i t}\right)$ and $\tau^{*}$ satisfy the following relations:

$$
\begin{aligned}
& \tau_{2}\left(h_{i t}\right)<\tau^{*} \Leftrightarrow h_{i t}>H_{2}\left(\tau^{*}\right), \\
& \tau_{1}\left(h_{i t}\right)>\tau^{*} \Leftrightarrow h_{i t}>H_{1}\left(\tau^{*}\right) .
\end{aligned}
$$

There are two cases that need to be considered: (i) $H_{1}\left(\tau^{*}\right)<H_{2}\left(\tau^{*}\right)$ and (ii) $H_{2}\left(\tau^{*}\right) \leq H_{1}\left(\tau^{*}\right)$. We start with case (i). Individuals with $h_{i t} \in\left[\hat{H}, H_{2}\left(\tau^{*}\right)\right)$ are unwilling to invest in education at $\tau_{t+1}=\tau^{*}$ since $\tau^{*}<\tau_{2}\left(h_{i t}\right)$. The welfare of such individuals is drawn in Figure 2(a). They prefer $\tau_{t+1}=0$. Individuals with $h_{i t} \geq H_{2}\left(\tau^{*}\right)$ are willing to invest in education at $\tau_{t+1}=\tau^{*}$ since $\tau_{2}\left(h_{i t}\right) \leq \tau^{*}$. The welfare of such individuals is depicted in Figure 2(b). Simple calculations show

$$
V^{E}\left(\tau^{*}, h_{i t}\right) \geq V^{N}\left(0, h_{i t}\right) \Leftrightarrow h_{i t} \geq \frac{1}{\left(\tau^{*}\right)^{\theta}-\tau^{*}} .
$$

Hence, these individuals prefer $\tau_{t+1}=\tau^{*}$ if $h_{i t} \geq 1 /\left[\left(\tau^{*}\right)^{\theta}-\tau^{*}\right]$ and prefer $\tau_{t+1}=0$ otherwise.

In case (ii), individuals with $h_{i t} \in\left[\hat{H}, H_{1}\left(\tau^{*}\right)\right)$ are not able to invest in education at $\tau_{t+1}=\tau^{*}$ since $\tau_{1}\left(h_{i t}\right)<\tau^{*}$. The welfare of these individuals is drawn in Figure 3(a). By simple calculations, we can see that $V^{E}\left[\tau_{1}\left(h_{i t}\right), h_{i t}\right]<V^{N}\left(0, h_{i t}\right)$ for any $h_{i t} \in\left[\hat{H}, H_{1}\left(\tau^{*}\right)\right)$. Hence, such individuals always prefer $\tau_{t+1}=0$. Individuals with $h_{i t} \geq H_{1}\left(\tau^{*}\right)$ have their children receive education at $\tau_{t+1}=\tau^{*}$, and the welfare of such individuals are depicted in Figure 3(b). Similarly to case (i), these individuals prefer $\tau_{t+1}=\tau^{*}$ if $h_{i t} \geq 1 /\left[\left(\tau^{*}\right)^{\theta}-\tau^{*}\right]$ and prefer $\tau_{t+1}=0$ otherwise. We summarize the results of this section in Proposition 1.

Proposition 1 Individual $i$ with $h_{i t}$ prefers $\tau_{t+1}=\tau^{*}$ if $h_{i t} \geq 1 /\left[\left(\tau^{*}\right)^{\theta}-\tau^{*}\right]$, and prefers $\tau_{t+1}=0$ otherwise.

\section{Majority Voting Equilibrium}

This section shows that the individual with median income is the decisive voter although the welfare of individuals over tax rates is not single-peaked as shown in Figures 2 and 3. The logic shares similarity with that of Glomm and Ravikumar [6]. Let $h_{m t}$ denote the human capital level of the individual with median income. If $h_{m t}<1 /\left[\left(\tau^{*}\right)^{\theta}-\tau^{*}\right]$, then the individual with median income prefers $\tau_{t+1}=0$. Since individuals with $h_{i t} \leq h_{m t}$, who comprise of fifty percent of the total population,

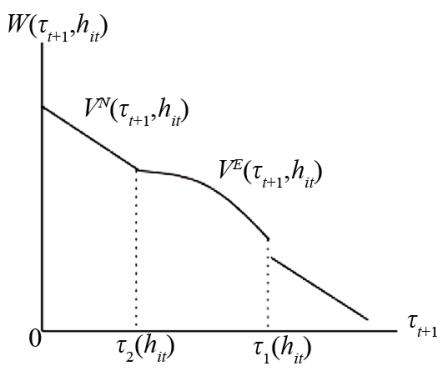

(a)

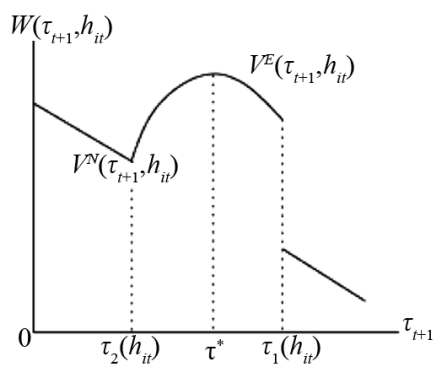

(b)

Figure 2. The welfare in case (i). 


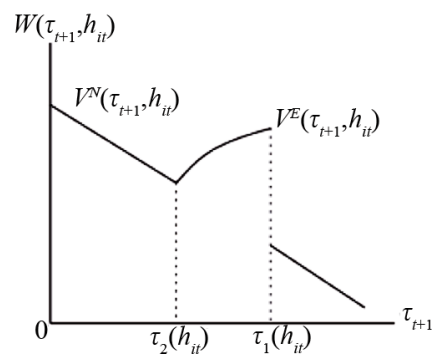

(a)

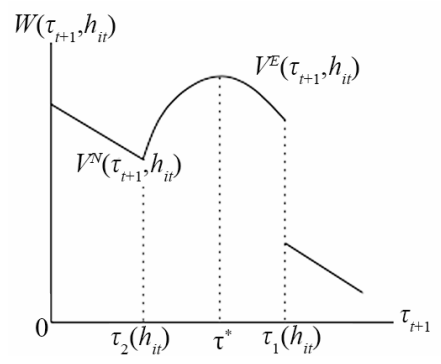

(b)

Figure 3. The welfare in case (ii).

also prefer $\tau_{t+1}=0$, there exists no tax rate that obtains more than fifty percent votes to beat $\tau_{t+1}=0$. If $h_{m t} \geq 1 /\left[\left(\tau^{*}\right)^{\theta}-\tau^{*}\right]$, then the individual with median income prefers $\tau_{t+1}=\tau^{*}$. Since individuals with $h_{i t} \geq h_{m t}$, who constitute fifty percent of the total population, also prefer $\tau_{t+1}=\tau^{*}$, no tax rate gains a majority vote to beat $\tau_{t+1}=\tau^{*}$. Hence, the individual with median income is the decisive voter.

Proposition 2 Under majority voting, $\tau_{t+1}=\tau^{*}$ if $h_{m t} \geq$ $1 /\left[\left(\tau^{*}\right)^{\theta}-\tau^{*}\right]$, and $\tau_{t+1}=0$ otherwise.

\section{The Result}

As described in Introduction, empirical evidence shows that high income inequality is associated with lower levels of education, public good provision and per capita income. In contrast to the results of Saint-Paul and Verdier [2], our model predicts that high inequality leads to less government expenditure on education. In the model, whether human capital is accumulated and the economy grows over time depends on the initial distribution of human capital, or income distribution. To understand this point, it should be noted that the child of the median voter is the median voter in the next period because human capital evolves according to (5) and (6).

$$
\text { If } h_{m 0} \geq 1 /\left[\left(\tau^{*}\right)^{\theta}-\tau^{*}\right] \text {, then } h_{m t} \geq 1 /\left[\left(\tau^{*}\right)^{\theta}-\tau^{*}\right]
$$

for all $t \geq 1$ since human capital does not depreciate. Hence, $\tau_{t}=\tau^{*}$ for all $t \geq 1$. All individuals in lineage $i$ such that $h_{i 0} \geq \max \left\{H_{1}\left(\tau^{*}\right), H_{2}\left(\tau^{*}\right)\right\}$ accumulate their human capital according to (5) with $\tau_{t}=\tau^{*}$. In contrast, all individuals in lineage $i$ such that $h_{i 0}<\max \left\{H_{1}\left(\tau^{*}\right), H_{2}\left(\tau^{*}\right)\right\}$ just inherit their parental human capital in all periods, i.e., $h_{i t}=h_{i 0}$ for all $t \geq 1$.

If $h_{m 0}<1 /\left[\left(\tau^{*}\right)^{\theta}-\tau^{*}\right]$, then government expenditure on education is zero and no one can obtain education provided by the government. This situation continues and $h_{i t}=h_{i 0}$ for all $t \geq 1$ and $i$. Proposition 3 summarizes these results.

Proposition 3 If $h_{m 0} \geq 1 /\left[\left(\tau^{*}\right)^{\theta}-\tau^{*}\right]$, then $\tau_{t}=\tau^{*}$ for all $t \geq 1$. All individuals in lineage $i$ such that $h_{i 0} \geq \max \left\{H_{1}\left(\tau^{*}\right), H_{2}\left(\tau^{*}\right)\right\}$ accumulate their human capital according to (5), while all individuals in lineage $i$ such that $h_{i 0}<\max \left\{H_{1}\left(\tau^{*}\right), H_{2}\left(\tau^{*}\right)\right\}$ never enhance their inherited human capital. If $h_{m 0}<1 /\left[\left(\tau^{*}\right)^{\theta}-\tau^{*}\right]$, then $h_{i t}=h_{i 0}$ and $\tau_{t}=0$ for all $t \geq 1$ and $i$.

When $h_{m 0} \geq 1 /\left[\left(\tau^{*}\right)^{\theta}-\tau^{*}\right]$, politically implemented public education accumulates the human capital of individuals in lineages whose initial human capital is greater than $\max \left\{H_{1}\left(\tau^{*}\right), H_{2}\left(\tau^{*}\right)\right\}$, and it stimulates economic growth. In contrast, when $h_{m 0}<1 /\left[\left(\tau^{*}\right)^{\theta}-\tau^{*}\right]$, public education is not implemented, and there is no human capital accumulation. These results imply that high initial inequality retards economic growth.

This paper has analyzed the relationship among income inequality, education and economic growth by focusing on two features of education, fixed costs and positive correlation between the return from education and the level of inherited human capital. Fixed costs of education are particularly relevant for post-compulsory education. The analysis on situations in which compulsory and post-compulsory education coexist would be a fruitful direction for further research.

\section{REFERENCES}

[1] T. Persson and G. Tabellini, "Is Inequality Harmful for Growth?” American Economic Review, Vol. 84, No. 3, 1994, pp. 600-621.

[2] G. Saint-Paul and T. Verdier, "Education, Democracy and Growth,” Journal of Development Economics, Vol. 42, No. 2, 1993, pp. 399-407. doi:10.1016/0304-3878(93)90027-K

[3] W. Easterly, "The Middle Class Consensus and Economic Development,” Journal of Economic Growth, Vol. 6, No. 4, 2001, pp. 317-335. doi:10.1023/A:1012786330095 
[4] W. Easterly, "Inequality Does Cause Underdevelopment: Insights from a New Instrument," Journal of Development Economics, Vol. 84, No. 2, 2007, pp. 755-776. doi:10.1016/j.jdeveco.2006.11.002

[5] E. Hanushek, "The Economics of Schooling: Production and Efficiency in Public Schools," Journal of Economic
Literature, Vol. 24, No. 3, 1986, pp. 1141-1177.

[6] G. Glomm and B. Ravikumar, "Opting out of Publicly Provided Services: A Majority Voting Result,” Social Choice and Welfare, Vol. 15, No. 4, 1998, pp. 187-199. doi:10.1007/s003550050099 